\title{
The effective application of a discrete transition model to explore cell-cycle regulation in yeast
}

\author{
Amir Rubinstein ${ }^{1}$, Ofir Hazan ${ }^{2}$, Benny Chor ${ }^{1}$, Ron Y Pinter ${ }^{3}$ and Yona Kassir ${ }^{4 *}$
}

\begin{abstract}
Background: Bench biologists often do not take part in the development of computational models for their systems, and therefore, they frequently employ them as "black-boxes". Our aim was to construct and test a model that does not depend on the availability of quantitative data, and can be directly used without a need for intensive computational background.

Results: We present a discrete transition model. We used cell-cycle in budding yeast as a paradigm for a complex network, demonstrating phenomena such as sequential protein expression and activity, and cell-cycle oscillation. The structure of the network was validated by its response to computational perturbations such as mutations, and its response to mating-pheromone or nitrogen depletion. The model has a strong predicative capability, demonstrating how the activity of a specific transcription factor, $\mathrm{Hcm} 1$, is regulated, and what determines commitment of cells to enter and complete the cell-cycle.

Conclusion: The model presented herein is intuitive, yet is expressive enough to elucidate the intrinsic structure and qualitative behavior of large and complex regulatory networks. Moreover our model allowed us to examine multiple hypotheses in a simple and intuitive manner, giving rise to testable predictions. This methodology can be easily integrated as a useful approach for the study of networks, enriching experimental biology with computational insights.
\end{abstract}

Keywords: Cell-cycle, Commitment, Budding yeast, Computational model, Regulatory networks, Simulation

\section{Background}

The fate of cells in response to changing signals is determined through regulatory networks [1]. The components, i.e. genes and proteins, are identified by experimental tools which also reveal interactions between these components. Computational modeling of these networks can help in elucidating their structure and properties, identifying missing components (designated nodes in computational models), and distinguishing between optional hypotheses regarding interactions (edges) between nodes. Computational models can be roughly described as either continuous, dynamic ones, or logical/Boolean ones [2-6]. The continuous models (either stochastic or employing differential equations) are detailed, yet are often computationally infeasible on a large scale, and require data such as kinetic constants or concentration levels, which are often

\footnotetext{
* Correspondence: ykassir@tx.technion.ac.il

${ }^{4}$ Department of Biology, Technion - Israel Institute of Technology, Haifa 3200003, Israel

Full list of author information is available at the end of the article
}

unavailable. The Boolean models, on the other hand, are computationally efficient, but their expressive power is rather limited $[7,8]$.

A richer, substantially more expressive yet computationally efficient logical approach, which is an extension of Boolean models, is a discrete transition model $[7,8]$. In the model suggested by Rubinstein et al. [7], each node assumes a non-negative initial state, which reflects its activity level at the onset of simulation. Regulation effects are represented by weighted edges, where positive or negative weights reflect activation or repression, respectively. Moreover, the effect of an edge can be subject to regulation by other nodes, reflecting essential dependencies between components. A uniform transition rule determines simultaneously how nodes' states change over time (which is also discrete). This model was applied for the study of entry into meiosis in budding yeast (an 8 node network), demonstrating the transient and sequential expression of its two master regulators [7]. Moreover, it was successfully used to discriminate between optional 


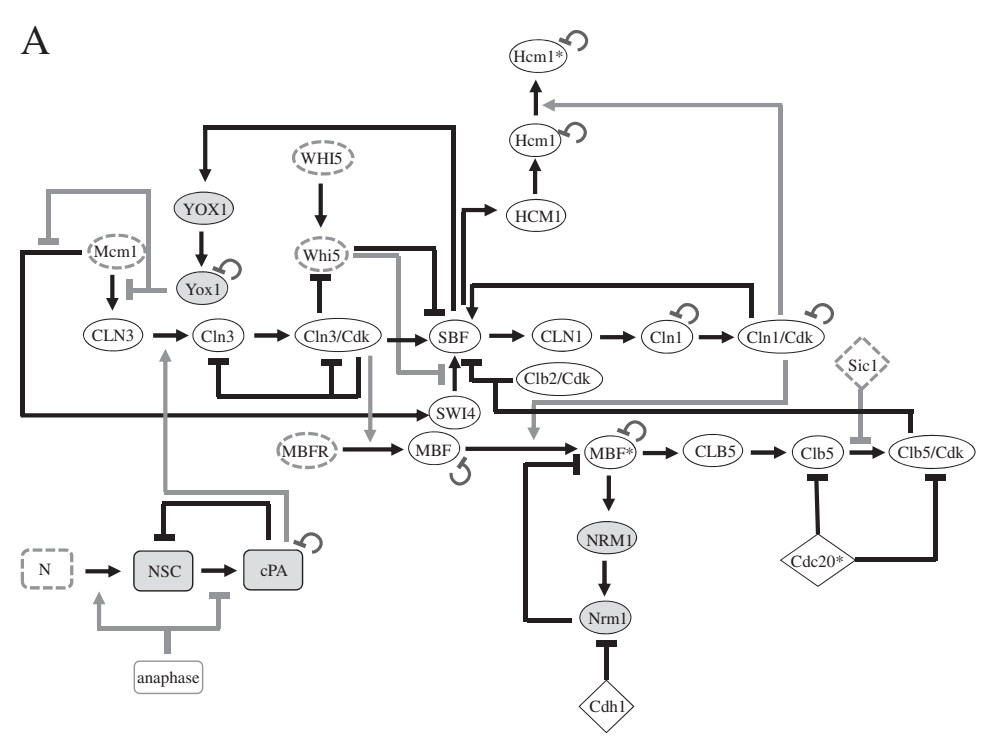

B

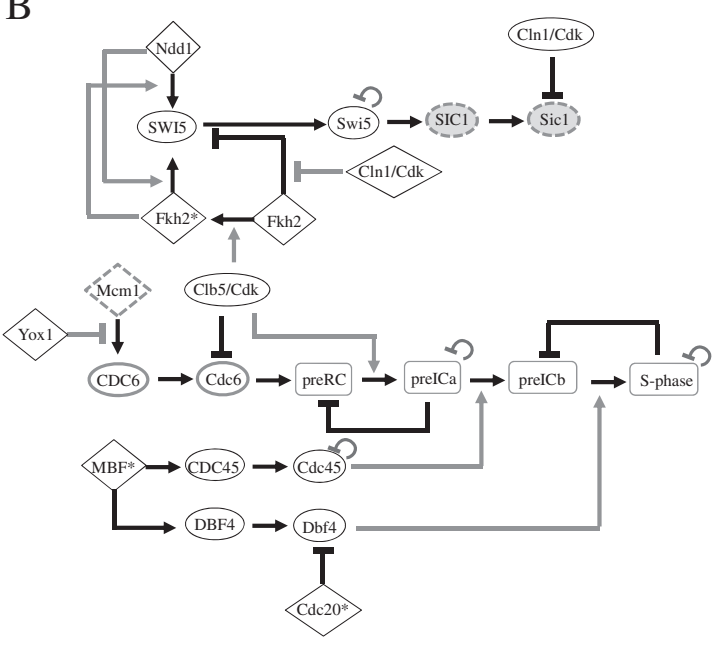

C

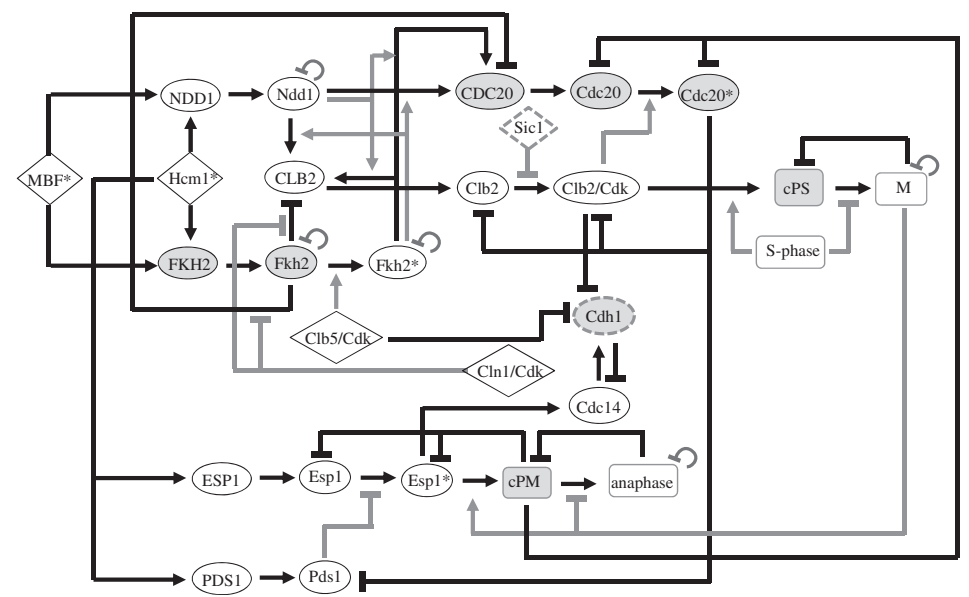

Figure 1 (See legend on next page.) 
(See figure on previous page.)

Figure 1 A Schematic view of the cell-cycle in S. cerevisiae. A. G1 and G1/S phases, B. S-phase, and C. G2 to anaphase. For simplicity we used this code to distinguish between the following: positive regulators - white ovals, negative regulators - gray ovals. Oval shapes with a dashed outline represent nodes with a constitutive state of 9 or whose initial state was 9 . White diamonds represent regulators whose regulation appears in another part of the figure. Rectangles represent cellular events (white) and checkpoints (gray). Positive edges - arrows, negative edges - lines with bars, dependency edges - gray arrows from a node to an edge. Self-edges represent negative auto-regulation. Details on the construction of the network are given in Methods.

hypotheses, revealing missing regulatory elements that were subsequently identified using experimental tools [7].

In the present work, we refine our discrete model [7] by generalizing its state transition function. The resulting model is rich enough to describe the oscillatory behavior of the cell-cycle in the budding yeast $S$. cerevisiae (a much larger 66 node network); to distinguish among several optional hypotheses regarding a specific transcriptional regulator, $\mathrm{Hcm} 1$; and to predict the condition required for traversing START (restriction point) [9].

\section{Results}

Construction of the S. cerevisiae cell-cycle network

We used the budding yeast cell-cycle as a paradigm for a complex biological regulatory system. Figure 1 shows a schematic representation of this network. For details see Methods. The network includes 67 nodes which represent important components (i.e. RNA, proteins, cellular events) required for proper transitions between all cellcycle phases. Redundant gene functions were represented in our network each by a single element. A checkpoint was modeled by a node whose level is induced by a specific regulator, but its ability to activate some other element depends on the absence of that regulator (Figure 2). For instance, the DNA replication checkpoint (cPS) is activated by S-phase, and it promotes metaphase only in the absence (completion) of S-phase [10] (Figure 1B).

\section{The discrete transition model exhibits oscillatory (periodic) and sequential behavior}

The initial states assigned to the nodes reflect a single cell at early G1 (see details in Methods). In general, a simulation goes on until either a steady state or an infinite loop is reached. Our simulation demonstrated oscillation, accurate and sequential progression through $S$-phase, entry into metaphase (M), and exit from metaphase (anaphase, A) (Figure 3A). Figure 3A shows two cell-cycles, but identical oscillations occurred infinitely (data not shown). Our simulation revealed the sequential and periodic expression of the G1, G1/S, S and M-phase cyclins, namely, Cln3, Cln1, Clb5, and Clb2 (RNA and proteins) and their activities (when in complex with Cdk1) (Figure 3A), as expected from experimental results (reviewed in $[11,12]$ ). Periodic and timely expression was also evident for all transcription factors that regulate the cell-cycle (Additional file 1), in agreement with experimental data. [13]. This validates the network structure and parameters.

We used our model to predict the behavior of cells in the absence of specific regulators (Figure 3). Gene deletion was simulated by excluding outgoing edges of the deleted genes. DNA replication depends on CDC6, which is essential for preRC formation [14]. Our simulation predicts that exclusion of CDC6 will result in cell-cycle arrest prior to S-phase entry (Figure 3C), in agreement with reported data [15]. Cdc6 is loaded on origins at telophhase $[16,17]$. Indeed, when the initial states of CDC6 RNA and protein were 9, reflecting the normal level at early G1 cells, cell cycle arrest prior to DNA replication was not immediate, and occurred only at the subsequent cell cycle (Figure 3B). This is in agreement with the results reported when unsynchronized cdc6-ts cells were shifted of to the non-permissive temperature [18]. Note that these cells showed the expected transient expression and activity of the cyclins and their corresponding Cdks, and then arrested without these cyclins (Figure 3, B and C. In B cells reached a steady state without cyclins at step 105). Excluding CLB2 (representing CLB1 and CLB2) outgoing edges predicted an arrest after completion of DNA replication, prior to entry into M-phase (Figure 3D). In accord, experimental results demonstrated that $\mathrm{Cdk} / \mathrm{Clb} 1,2$ are indeed required for entry into M-phase [19]. Exclusion of CDC20 resulted in a cell-cycle arrest prior to entry into anaphase, with high levels of Clb2 (Figure 3E). This prediction was confirmed, as CDC20 is required [in a complex with $\mathrm{APC} / \mathrm{C}$ [20]] for exit from metaphase [21]. Since

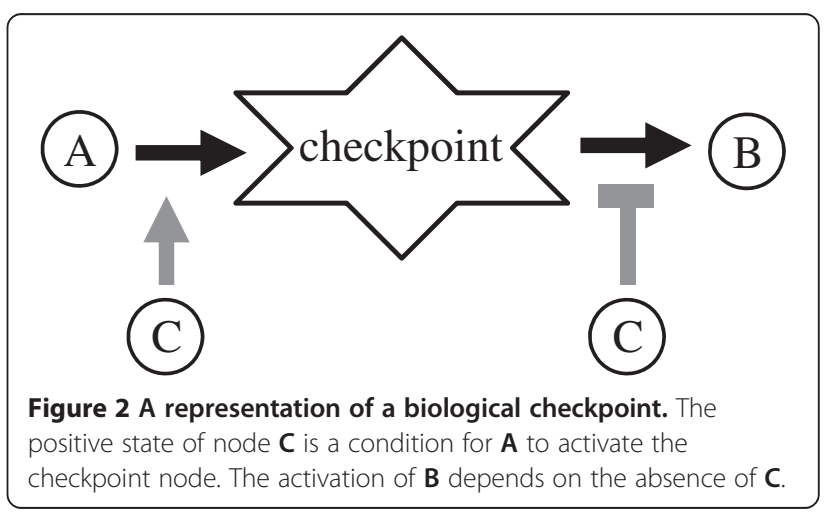




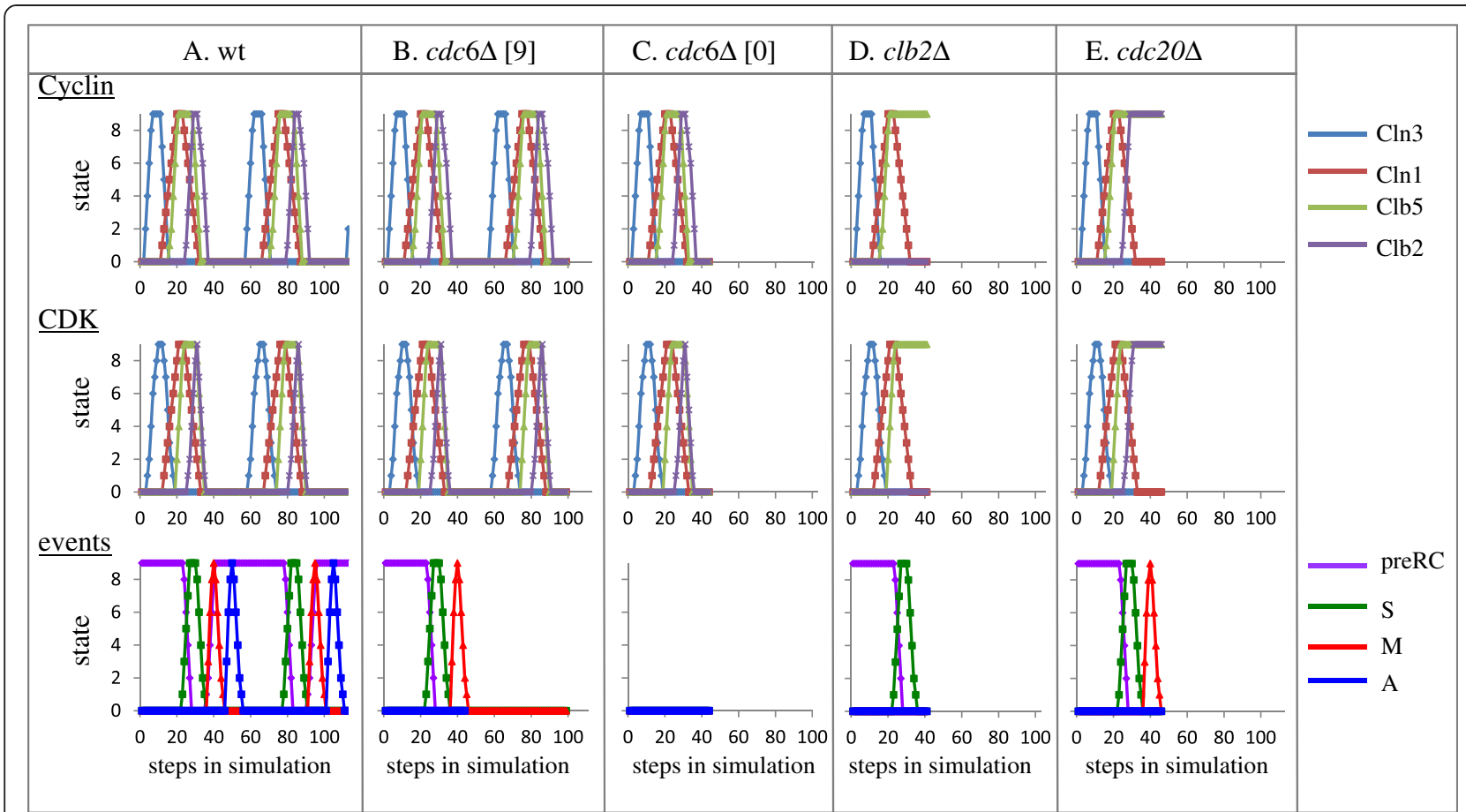

Figure 3 Simulation of the network under normal conditions of wild type and mutant strains. A. wild-type. B. and $\mathbf{C}$. cdc $6 \Delta$. The initial states of CDC6 and Cdc6 are either 9 (B) or 0 (C). D. clb2 $\triangle$, E. cdc20 $\Delta$. In A oscillations continued infinitely, whereas in B-E simulation reached steady state and all steps are shown.

$\mathrm{Clb} 2 / \mathrm{Cdk}$ is required to activate Cdc20 [22], its exclusion also caused an arrest with high levels of Clb5 (Figure 3E) whose degradation depends on Cdc20 [23]. In conclusion, the simulations of the various mutants gave rise to predictions that were confirmed by wet experiments.

\section{Cell-cycle commitment}

Entry into the cell-cycle depends on external and internal signals. Within G1 there is a specific point designated START or restriction point, after which cells become committed to the cell-cycle, and will complete it even in the absence of a signal [9]. In order to examine how single cells, at different cell-cycle stages, respond to perturbations, we conducted simulations with initial nodes' states that were reached in various intermediate steps of the normal conditions simulation. These initial states represent cells in G1, G1/S, S, M and A. We wished to use our model to determine how cells respond to $\alpha$-factor or nitrogen depletion, and either arrest immediately in G1, or following completion of a cell-cycle.

Treatment with $\alpha$-factor leads to inhibition of Cln3/ Cdk and $C \ln 1 / C d k$ functions [24-26]. Simulations showed that treatment with $\alpha$-factor resulted in cell cycle arrest as a steady state was reached. Cells in which Cln3/Cdk was not yet active (early G1) exhibited immediate cell-cycle arrest prior to the transcription of the
G1 cyclin CLN1 and entry into S-phase (Figure 4), as reported [27-29]. Cells that were already in S-phase, M-phase or anaphase completed the cycle and arrested in G1, with high levels of CLN3 RNA and protein, but CLN1, CLB5 and CLB2 RNA and proteins were absent (Figure 4). Commitment to the cell-cycle, namely entry into S-phase, occurred only in cells in which the activity of $\mathrm{Clb5} / \mathrm{Cdk}$ was induced (Figure 4, compare G1 to G1/ $\mathrm{S}$ cells). Note that at the onset of simulation $\mathrm{Clb} 5 / \mathrm{Cdk}$ was not active in both G1 and G1/S (Figures 4, and 5B), although the $\mathrm{Clb} 5$ protein was induced. Since the activity of $\mathrm{Clb} 5 / \mathrm{Cdk}$ is inhibited by Sic1 [30], we examined its level in these cells. Cells able to activate $\mathrm{Clb5} / \mathrm{Cdk}$ showed a transient elimination of Sic1 (Figure 5B, step 18). In contrast, cells that were shifted to pheromone one step earlier, exhibited only a decline in the level of Sic1 (Figure 5B, step 17). This result points to Sic1 as the indicator for commitment, as previously suggested $[31,32]$.

We further examined if the commitment actually depended directly on Sic1 or actually on its upstream regulator. Degradation of Sic1 depends on $\mathrm{Cln} 1 / \mathrm{Cdk}$ [33]. In accord, the level of Cln $1 / C d k$ was higher in cells able to complete the cycle, in comparison to cells that showed immediate arrest (Figure 5B, compare cells switched at step 18 and step 17). Thus, the low level of $\mathrm{Cln} 1 / \mathrm{Cdk}$ (node at state 1 enabled only a decline in Sic1 state (Figure 5B, step 17). On the other hand, when 


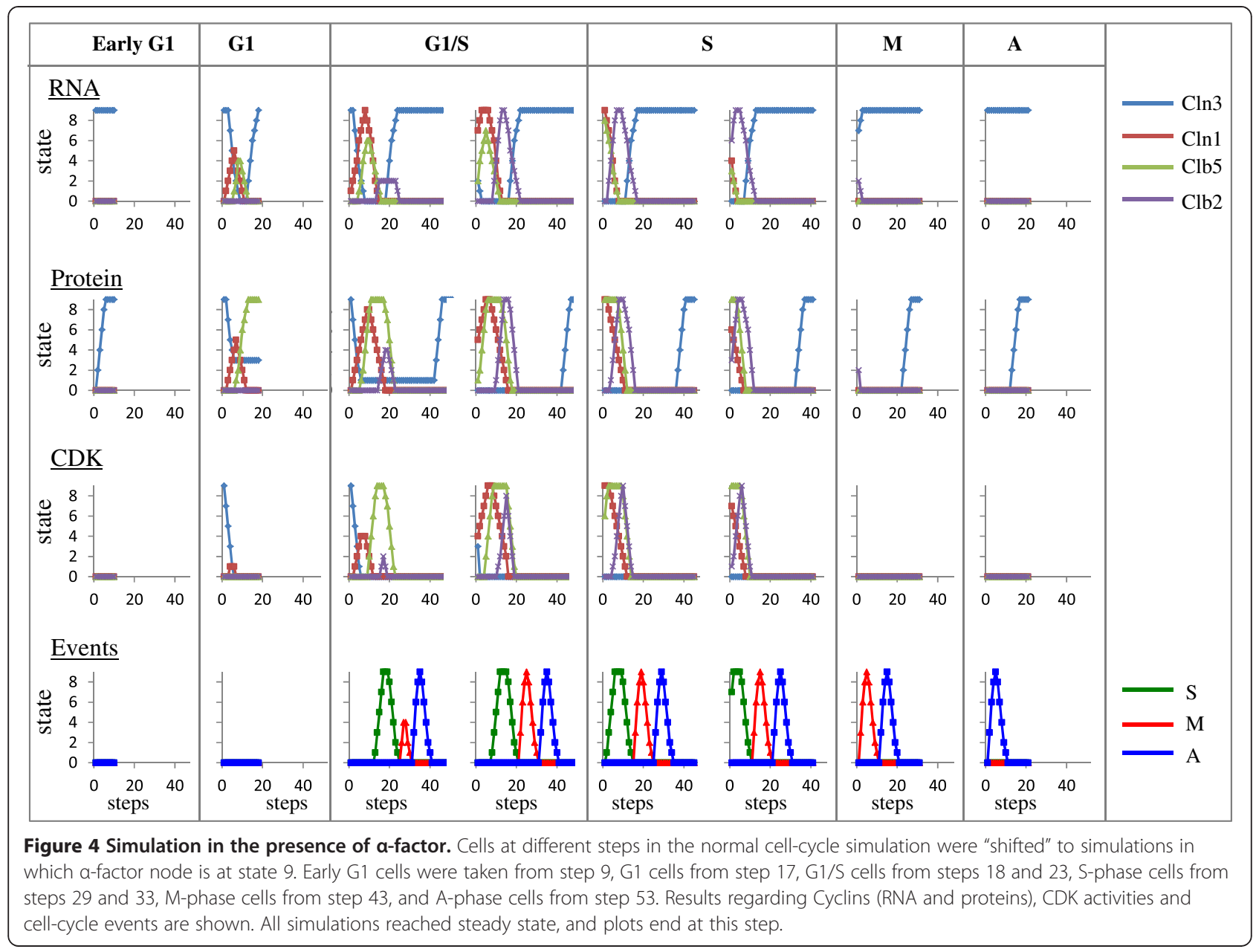

Cln1/Cdk level reached the higher state of 4, Sic1 was completely degraded (Figure 5B, step 18). This analysis suggests that the ability of Cln1/Cdk to destabilize Sic1 defines the point of no return, namely traversing through "Start", and that a threshold state/level of Cln1/Cdk is required for this effect. In agreement, using single-cell analysis, it was concluded that, the induction of $\mathrm{Cln} 1 / 2$ feedback, which results in higher activity of $\mathrm{Cln} 1 / \mathrm{Cdk}$, provides a biochemical definition for Start [34].

Under normal conditions the level of Cln1 mirrors the level of $\mathrm{Cln} 1 / \mathrm{Cdk}$ (Figure 3A). On the other hand, following pheromone treatment, the level of $\mathrm{Cln} 1 / \mathrm{Cdk}$ is lower than expected (Figures 5A and 5B). This suggests that an additional factor plays an important role in cellcycle commitment. Far1* (the active, phosphorylated form of Far1) inhibits Cln1/Cdk function [24], whereas Cln1/Cdk destabilizes Far1 [35]. We examined, therefore, the effect of Far1* on the level of the Cln1/Cdk. Cells switched at step 18 showed a delay in the increase of Far1* in comparison to the time of induction of Cln1/ Cdk (Figure 5B). On the other hand, cells switched at stage 17 showed an earlier induction of Far1*, at the same time as that of $\mathrm{Cln} 1 / \mathrm{Cdk}$ (Figure $5 \mathrm{~B}$ ). We conclude, therefore, that $\mathrm{Cln} / \mathrm{Cdk}$ activity defines commitment, and that under pheromone induction this activity is regulated by the double negative feedback loop between Cln $1 / \mathrm{Cdk}$ and Far 1 , as previously suggested [34].

Nitrogen depletion leads to G1 arrest [36]. It is assumed that its main target is the G1 cyclin, CLN3, as nitrogen starvation inhibits CLN3 mRNA translation [37], increases Cln3 protein degradation [37], and retains $\mathrm{Cln} 3$ in the cytoplasm [38]. It was speculated that nitrogen depletion has an additional target, since cells that are deleted for CLN3 properly arrest in G1 following nitrogen depletion. Our simulation reinforces this speculation, as nitrogen depletion promoted cell-cycle arrest, mainly in G1, but a specific subpopulation arrested in G2, after completion of DNA replication and prior to entry into M-phase (Table 1, hypothesis 1)). This result suggests that indeed nitrogen depletion must affect an additional regulator. Two possible targets were previously suggested: SIC1 mRNA availability (hypothesis 2) or Cln1/2 stability (hypothesis 3) [37]. Simulations of these two hypotheses resulted in the correct G1 arrest 


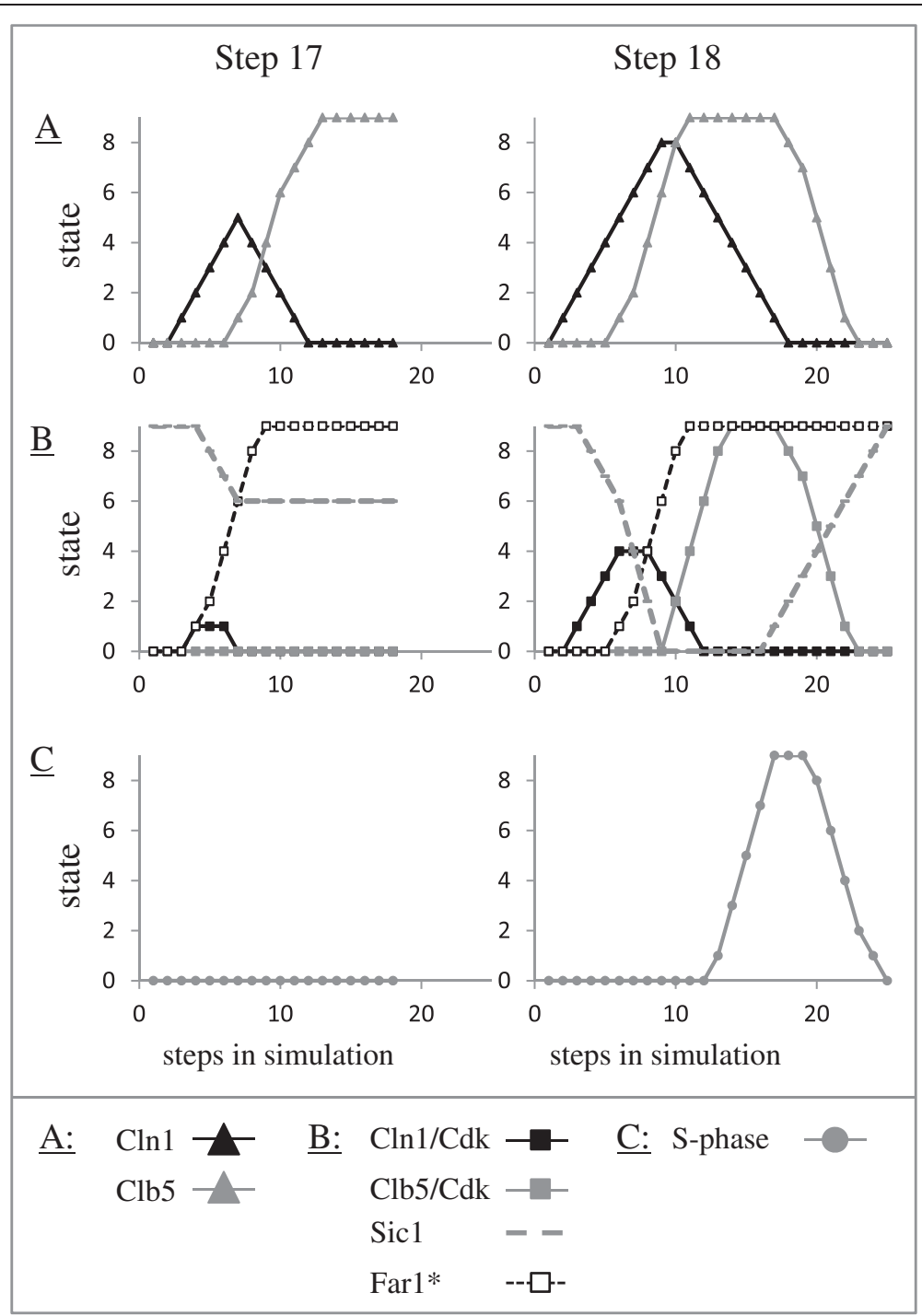

Figure $\mathbf{5}$ Commitment to the cell cycle is determine by the level of $\mathrm{Cln} 1 / \mathrm{Cdk}$. Simulation in the presence of a-factor as in Figure 4. A. Cln1, Clb5, B. Cln1/Cdk, Clb5/Cdk, Far1*, Sic1, C. S-phase.

(Table 1). In order to discriminate between these two hypotheses we conducted simulations of a strain expressing a stable $C \ln 1$ protein. This approach was based on the report that cells which express a stable Cln2 protein (CLN2-1 allele) respond to nitrogen depletion by arresting the cell-cycle at multiple points, not only in G1 [39].
Simulation of hypothesis 2 network resulted in the arrest of all cells in G1, whereas simulation of hypothesis 3 network resulted in the correct behavior, namely arrest in both G1 and G2 (Table 1). Our results predict, therefore, that nitrogen depletion also affects the stability of $C \ln 1$.

Table 1 Simulations predict that nitrogen depletion affects both Cln3 and Cln 1

\begin{tabular}{|c|c|c|c|}
\hline \multirow[t]{3}{*}{ Hypotheses } & \multirow[t]{3}{*}{ Possible nitrogen depletion targets } & \multirow{2}{*}{\multicolumn{2}{|c|}{$\begin{array}{l}\text { Results of simulations } \\
\text { Point of cell-cycle arrest }\end{array}$}} \\
\hline & & & \\
\hline & & Wild-type & Stable Cln 1 \\
\hline Hypothesis 1 & $\mathrm{Cln} 3, \mathrm{Cln} 3 / \mathrm{Cdk}$ & G1 and $G 2$ & G1 and G2 \\
\hline Hypothesis 2 & $\mathrm{Cln} 3, \mathrm{Cln} 3 / \mathrm{Cdk}$, SIC1 transcription & G1 & G1 \\
\hline Hypothesis 3 & $\mathrm{Cln} 3, \mathrm{Cln} 3 / \mathrm{Cdk}, \mathrm{Cln} 1, \mathrm{Cln} 1 / \mathrm{Cdk}$ & G1 & G1 and G2 \\
\hline
\end{tabular}

Cells at different steps in the normal cell-cycle simulation were "shifted" to simulations in which Nitrogen was depleted. 
The use of our model to predict the Cdk/cyclin complex that regulates $\mathrm{Hcm} 1$

The transient expression of Hcm 1 is not required for the transient transcription of its target genes [13]. Because $\mathrm{Hcm} 1$ is subject to post-translational modification, it was suggested that this modification affects its activity during the cell cycle [13]. Since Hcm1 is a probable Cdk target [40] we examined if this regulation is mediated by either $\mathrm{Cln} 3 / \mathrm{Cdk}, \mathrm{Cln} 1 / \mathrm{Cdk} 1$ or $\mathrm{Clb} 5 / \mathrm{Cdk}$ (Figure 6). Simulations revealed that activation of $\mathrm{Hcm} 1$ by $\mathrm{Cln} 3 /$ $\mathrm{Cdk}$ resulted in premature decline in the transcription of CLB2 in relation to S-phase (Figure 6B, upper panel). On the other hand, regulation by either $\mathrm{Cln} 1 / \mathrm{Cdk}$ or $\mathrm{Clb} 5 / \mathrm{Cdk}$, showed the expected behavior (Figure 6B, middle and lower panels). In order to discriminate between the latter two hypotheses, we examined the response of cells to pheromone treatment. Regulation by Clb5/Cdk showed an abnormal phenotype, namely some G1cells arrested after completion of S-phase (Figure 6C). Our simulations predict that $\mathrm{Cln} 1 / \mathrm{Cdk}$ rather than $\mathrm{Clb} 5 / \mathrm{Cdk}$ or $\mathrm{Clb} 2 / \mathrm{Cdk}$, is responsible for regulating the activity of Hcm1. All simulations in this report were done according to this prediction.

\section{Discussion}

The analysis of regulatory networks by computational methods is often quantitative in nature. However, due to lack of complete quantitative kinetic data in many cases, these methods are not applicable. Moreover, the use of these methods requires intensive computational skills, and are typically applied by either trained bioinformaticians or employed in a collaborative, interdisciplinary manner. Experimental biologists, by themselves, rarely incorporate these methods in their routine research, and often refrain from reviewing the computational analyses in scientific literature. Consequently, manuscripts which include intense use of mathematical equations are less frequently cited by experimental biologists [41]. Furthermore, the use of existing bioinformatics tools by scientists who lack intensive background in bioinformatics may result in misinterpretation of simulation results and in erroneous conclusion making [42].

In this report we demonstrate that a simple discrete model can suffice for the qualitative analysis of important network properties, but still remain intuitive for use without extensive computational background. Indeed, our results could not have been reached without a repeated, intuitive, refinement process, made of numerous simulations conducted directly by a biologist. This type of model is a "middle ground" between Boolean methods, which are claimed to gradually fall out of favor [4], and quantitative models. Additional file 1 describes the simple mode by which interested scientists can apply this model, using the tool we implemented. As

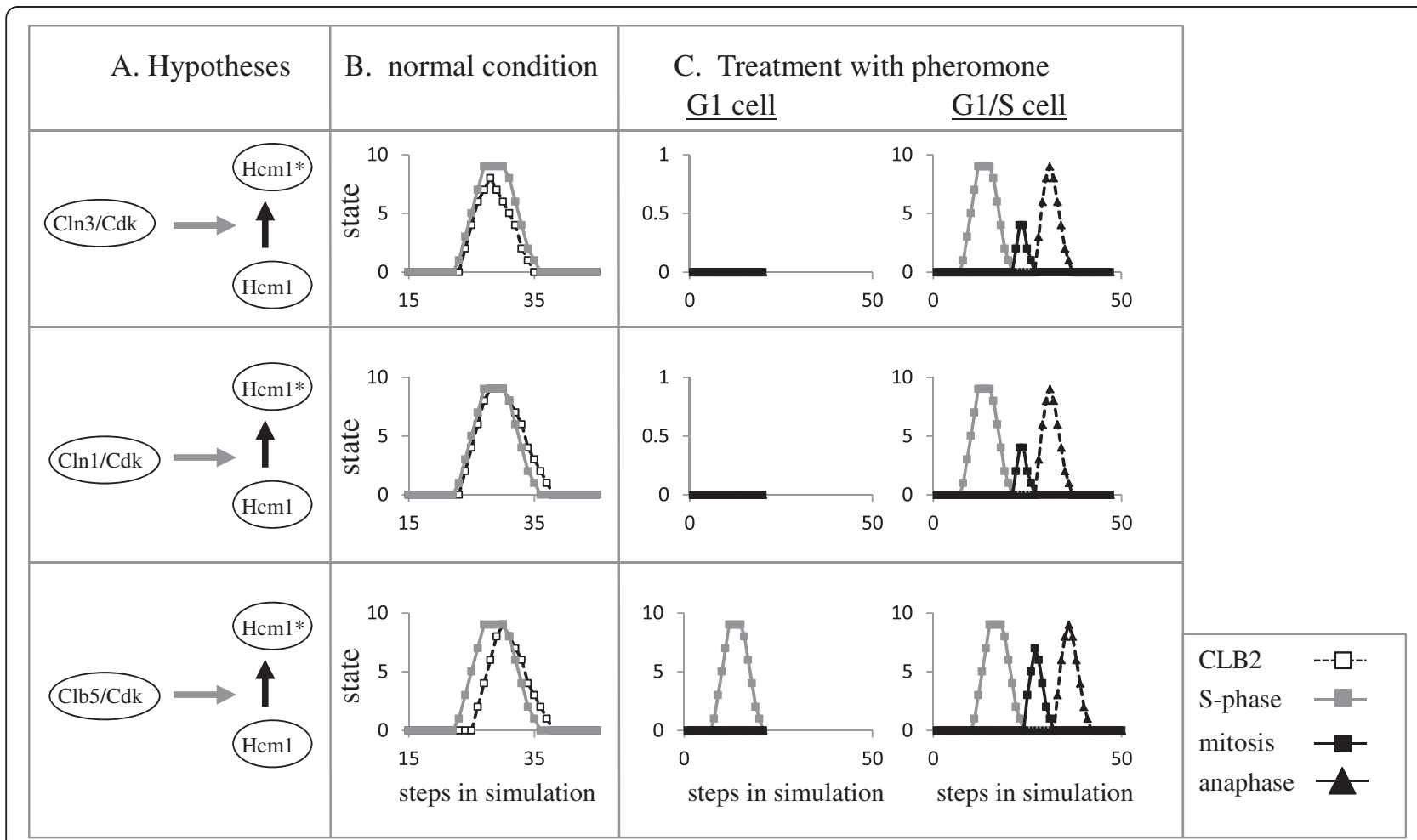

Figure 6 Hypotheses regarding how $\mathbf{H c m} \mathbf{1}^{*}$ activity is regulated. A. hypotheses; $\mathbf{B}$. levels of CLB2 and S-phase; $\mathbf{C}$. levels of S-phase, mitosis and anaphase in a-factor treatment of cells taken from G1 and G1/S stages. 
described, this process requires only a straightforward conversion of a biological network into a specified format.

We applied our model to the yeast cell-cycle network demonstrating cell-cycle oscillation (Figures 3 and Additional file 1). The network included 67 nodes, 60 of which showed the reported sequential and periodic expression (the other 7 were either constitutively present or active only under pheromone treatment) (Figures 3 and Additional file 1). Thus, the model effectively demonstrated the correct behavior of a fairly large and non-linear network. Predictions showing an arrest at three essential points: prior to entry into S-phase, metaphase, or anaphase (Figure 3) were confirmed by published data.

Entry of eukaryotic cells into alternative differentiation pathways is usually executed at G1 [36] Thus, signals that regulate these developmental pathways will first lead to arrest in G1 and subsequently to entry into the new developmental pathway. Consequently, within G1 there is a point, START, prior to which cells will respond by immediate arrest at G1, whereas cells that passed this point are committed to complete the cell-cycle and only then arrest in G1. In this report, using our discrete model, we examined how yeast cells respond to either the mating (pheromone) or nitrogen depletion signals. We show that as reported, cells are divided into preand post- START (Figure 4). Pre-START cells showed an immediate arrest, whereas post-START cells where committed, completed the cell cycle, and then arrested in G1 (Figure 4 and Table 1).

Simulation in the presence of pheromone allowed us to identify the component whose expression/activity defined START. We showed that $\mathrm{Cln} 1 / \mathrm{Cdk}$ expression is required for commitment. Moreover, Cln1/Cdk level was important, as a low state of 1 for that node did not suffice for traversing the cell cycle. Finally, our results point to the double-negative feedback loop between Cln1/Cdk and Far $1^{*}$ as an important parameter in regulating the level of $\mathrm{Cln} 1 / \mathrm{Cdk}$, and consequently the commitment stage (Figure 5), reinforcing a previous conclusion that was based on experimental results and modeling by differential equations [34].

Simulation under nitrogen depletion allowed us to predict the targets for this signal. We showed that an effect only on Cln3 did not suffice for an arrest of all cells in G1, and that in addition, starvation also affected the availability of Cln1 (Table 1). Moreover, our simulations refute the hypothesis that SIC1 is an essential target of nitrogen depletion (Table 1). This demonstrates the predictive capability of our model. We also examined 3 hypotheses regarding the regulation of $\mathrm{Hcm} 1$ activity. The model predicted that $\mathrm{Cln} 1 / \mathrm{Cdk}$, rather than $\mathrm{Cln} 3 / \mathrm{Cdk}$ or $\mathrm{Clb} 5 / \mathrm{Cdk}$, mediates this regulation (Figure 6). In conclusion, our model allowed us to examine multiple hypotheses in a simple and intuitive manner, giving rise to testable predictions.

The number of nodes used, 67, in this study does not represent the complete cell-cycle regulatory network. Our network (Figure 1) can be used as a starting point for an in-depth, focused analysis of specific cell-cycle events. For instance DNA-replication, G2-M transition, exit from metaphase, or checkpoint regulation. Our model is available upon request.

\section{Conclusions}

We present a simple and intuitive model that does not depend on the availability of quantitative data, and can be directly used without a need for intensive computational background. This methodology can be easily integrated as a useful approach for the study of networks, enriching experimental biology with computational insights. The validity of the model was tested on a large and complex network, cell cycle in budding yeast. We verified the structure of the cell cycle network by simulations of various mutants. The model has a strong predictive feature that can be easily used to distinguish between alternative hypotheses. Herein the model was used to predict the following: 1 . Cln $1 / \mathrm{Cdk}$ rather than $\mathrm{Cln} 3 / \mathrm{Cdk}, \mathrm{Clb} 5 / \mathrm{Cdk}$ or $\mathrm{Clb} 2 / \mathrm{Cdk}$, is responsible for regulating the activity of $\mathrm{Hcm} 1$, and (2). Simulations in the presence of $\alpha$-factor predict that commitment to enter the cell cycle depends on a double-negative feedback loop between $\mathrm{Cln} 1 / \mathrm{Cdk}$ and Far1*.

\section{Methods}

\section{The computational model}

Our model is an extension of the discrete transition model suggested by [7]. In this model, nodes represent mRNA's, proteins, nutrients, or cellular events. Each node assumes an initial discrete state taken from a fixed range $\{0, \ldots, U\}$ [e.g. $U=9$, as in our simulations, chosen for technical reasons, see [7]], and this state may change over time. Edge $(i, j)$ acquires a positive (activation) or negative (repression) weight w(i,j). "Dependency edges", going from some node $k$ to an edge $(i, j)$, introduce dependent regulation effects: In order for $i$ to regulate $j$, node $\mathrm{k}$ must be active (positive dependency) or inactive (negative dependency). A configuration of the system is a vector of all the nodes' states. A transition function determines the next state of each node, given its current state, the states of its neighbors and the weights of its incoming edges. A simulation step is an application of the transition function simultaneously to all nodes in the system. Steps occur in discrete times $t=1, t=2$ and so on. A simulation is a consecutive application of the transition function forming a sequence of steps, starting from a designated initial configuration, and continuing until either a steady state is reached (two consecutive 
identical configurations), or an infinite loop of configurations is detected.

We extend the model's transition function, which appears in Formula 1. $\mathrm{s}_{\mathrm{i}}(\mathrm{t})$ is the state of node $\mathrm{i}$ at time $\mathrm{t}$. The term $\operatorname{sum}_{\mathrm{i}}(\mathrm{t})$ captures the total effect on node $\mathrm{i}$ at time $\mathrm{t}$ by all its neighbors. We remark that $\operatorname{cond}(j, i)=1$ if all dependency conditions on edge $(\mathrm{j}, \mathrm{i})$ hold, and 0 otherwise. If $\operatorname{sum}_{\mathrm{i}}(\mathrm{t})$ exceeds the upper threshold of node $\mathrm{i}\left(\right.$ threshold $_{\mathrm{i}}^{+}$) its state will increase in the next time step, while if it is below the lower threshold (threshold $\mathrm{i}_{\mathrm{i}}^{-}$) its state will decrease. The update is (in the first two cases) some function $\mathrm{f}$ of $\operatorname{sum}_{\mathrm{i}}(\mathrm{t})$. In [7], $f=1$, whereas we introduced a logarithmic-order transition function, $f\left(\right.$ sum $_{i}$ $(t))=\left[\ln \left(\left|\operatorname{sum}_{i}(t)\right|+1\right)\right]$. We note that the logarithmic function avoids the problematic nature of, e.g., linear functions, which cause changes which are too extreme, and of constant change functions, that are not sufficiently differential. This enriched model enables the transition function to reflect differential strengths of regulation effects, such as different elements showing faster increase or decrease of activity, compared to others.

\section{Formula 1: The extended transition function}

$$
s_{i}(t+1)=\left\{\begin{array}{ccc}
\min \left(U, s_{i}(t)+f\left(\operatorname{sum}_{i}(t)\right)\right. & \text { if } & \text { sum }_{i}(t)>\text { threshold }_{i}^{+} \\
\max \left(0, s_{i}(t)-f\left(\operatorname{sum}_{i}(t)\right)\right. & \text { if } & \text { sum }_{i}(t)<\text { threshold }_{i}^{-} \\
s_{i}(t) & \text { otherwise }
\end{array}\right\}
$$

The model was implemented in C\# using Visual Studio.NET, and analyses procedures of simulation results were implemented as VBA macros.

\section{Construction of the cell cycle network}

The following general considerations were used to construct the network (Figure 1). Redundant gene functions were represented in our network each by a single element. Periodic availability/activity requires that each node is subject to both positive and negative inputs. RNAs are non-stable molecules, nonetheless in most cases there is no information regarding the control of mRNA stability. Therefore, in the network, we simulated the intrinsic stability of the RNAs by using negative auto-regulation. In many cases, reported results demonstrated periodic expression of proteins, however, only in few cases information was reported regarding how these proteins' stability is regulated. Therefore, in order to simulate this behavior we either used negative auto regulation, or negative feedback regulation. Some proteins are represented by two nodes: unmodified and modified (labeled with a star). Essential regulatory elements are present as dependencies edges.

The information used to construct the cell cycle network is described below. The G1 and G1/S transition (Figure 1A): Entry into the cell cycle from G1 depends on both the availability of nutrients $(\mathrm{N})$ and the completion of anaphase. The major regulator is $\mathrm{Cln} 3 / \mathrm{Cdk} 1$ (Cdklis designated inhere as Cdk). Cdk expression is constitutive, while the transcription of CLN3 is regulated by Mcm1, a constitutive expressed TF (level 9 throughout the simulation). Mcm1 activity is repressed by Yox1 [43] (Yox1 regulation will be described below). The translation and stability of $\mathrm{Cln} 3$ protein is subject to multiple regulations by nutrients $[37,44,45]$. We assumed that depending on anaphase, nutrients regulate a nutrient sensing node (NSC), and that this node regulates a checkpoint (cPA) whose availability depends on the completion (absence) of anaphase. We further assumed that the translation of $\mathrm{Cln} 3$ depends on this checkpoint. Finally, Cln3 is degraded following phosphorylation by Cdk [46]. We assume that this regulation is mediated through the $\mathrm{Cln} 3 / \mathrm{Cdk}$ complex. $\mathrm{Cln} 3 / \mathrm{Cdk}$ promotes the activity of two transcription factor complexes, SBF and MBF. SBF represses transcription when it consists of Swi4/Swi6/Whi5, and activates transcription when Whi5 dissociates from the complex. The transcription of WHI5 is regulated by Hcm1* [13]. However, because in cells deleted for HCM1 its transcription is constitutive, but less than the wild type level [13], we omitted regulation by $\mathrm{Hcm}_{1 *}^{*}$, and designated its regulation as constitutive, with initial level of 5 . The activity of Whi5 is negatively regulated by $\mathrm{Cln} 3 / \mathrm{Cdk}$, an event that causes its dissociation from the complex [47]. In order to prevent entry into the cell cycle until $\mathrm{Cln} 3 / \mathrm{Cdk}$ is available, the initial state of Whi5 was 5 .

The transcription of SWI4 is regulated in the same manner as that of CLN3 [43]. In the network SWI4 regulates SBF formation. For simplicity, we did not separate SBF into its repression and activation complexes. Instead, the essential repression functions of Whi5 [48,49] was modeled as a dependency edge that inhibits the ability of Swi4 to activate SBF, as well as by a direct negative regulation on SBF. In addition, the function of SBF is positively regulated by both $\mathrm{Cln} 3 / \mathrm{Cdk}$ and $\mathrm{Cln} 1 / \mathrm{Cdk}$ $[29,50]$. SBF function is negatively regulated by $\mathrm{Clb} 2 /$ Cdk [51] as well as by Clb6/Cdk, as phosphorylation of Swi6 by Clb6/Cdk leads to the export of Swi6 from the nucleus to the cytoplasm. Dephosphorylation of Swi6 by Cdc14 promotes nuclear import, in preparation for a new cell cycle [52]. This effect is designated in the network as an edge from $\mathrm{Clb5} / \mathrm{Cdk}$.

The transcription of YOX1 is periodic, regulated by SBF $[13,43]$. Both SBF and MBF bind to the HCM1 promoter [53]. These transcription factors have 
apparently redundant functions, because deletion of both TFs was required in order to observe an effect on its transcription [54]. The network includes regulation by only one complex - SBF, which is functional prior to MBF. The Hcm 1 protein shows periodic expression [13], we assume that this is due to its intrinsic stability, similarly to Yox1. Hcm 1 is switched to the active Hcm 1 * depending on Cln1/Cdk (see rational in Figure 6 and text).

The transcription of CLN1 is regulated by SBF $[49,55]$. Expression of $\mathrm{Cln} 1$ is periodic; we assume that this is due to $C \ln 1$ intrinsic stability.

$\mathrm{MBF}$ is detected on promoters throughout the cell cycle, although at most times it represses transcription [56]. Transcriptional activation by MBF depends on both Cln3/Cdk and Cln1/Cdk. Therefore, we divided this complex into 3 nodes: MBFR (for repressive), MBF, and $\mathrm{MBF}^{*}$ (for active). MBFR level is constitutive 9. MBFR is switched to $\mathrm{MBF}$ depending on $\mathrm{Cln} 3 / \mathrm{Cdk}$, whereas $\mathrm{MBF}$ is switched to $\mathrm{MBF}^{*}$ depending on $\mathrm{Cln} 1 / \mathrm{Cdk}$. The level of MBF is decreased depending on self-degradation. Activity of $\mathrm{MBF}^{*}$ is inhibited by Nrm1 [56]. In cells deleted for NRM1 the transcription of MBF targets is still periodic [56], and because we do not know who is responsible for this effect, we put self-degradation on $\mathrm{MBF}^{*}$.

The transcription of NRM1 is regulated by MBF* [56]. The periodic expression of Nrm1 is mediated by degradation via Cdh1/APC [57]. MBF* regulates the transcription of CLB5. The periodic expression of Clb5 and Clb5/ $\mathrm{Cdk}$ is mediated by degradation from $\mathrm{APC} / \mathrm{C} / \mathrm{Cdc} 20^{*}$ $[21,23]$. The level of APC/C is constitutive, but its activity depends on its association with either Cdh1 or Cdc20 [20]. Therefore, in our network, Cdc20* represents APC/ Cdc20. In addition, stability of Clb5 depends on an additional proteasome depending factor whose identity is still not known [58]. As this unknown regulation is absent from our network, the level of Clb5 was not reduced to 0 upon treatment with pheromone. Finally, the activity of Clb5/Cdk depends on the absence of Sic1 [30].

Entry into S-phase (Figure 1B): DNA replication is a complex process that depends on many proteins. In the network presented in here we used only few proteins that suffice to define its separation to distinct phases/ complexes. Below we first describe the regulation of these proteins and then how they are used to regulate DNA replication. The transcription of CDC6 is positively regulated by $\mathrm{Mcm} 1$ depending on the absence of Yox1 [43]. The periodic availability of Cdc6 is accomplished through negative regulation from $\mathrm{Clb} 5 / \mathrm{Cdk}$ $[59,60]$. Cdc6 is present prior to $\mathrm{G1}$, and therefore, the initial levels of CDC6 and Cdc6 were given the state 9. The transcription of CDC45 and DBF4 are positively regulated by $\mathrm{MBF}^{*}[53,61]$. Cdc45 availability is regulated by intrinsic stability. In order to shorten and control time of expression, the positive and negative regulations edges were assigned the weight 2 . The stability of Dbf4 is regulated by $\mathrm{APC} / \mathrm{Cdc} 20$ [62]. PreReplication Complex (preRC) formation is regulated by Cdc6 [14]. The preRC complex was switched to PreIC depending on Clb5/Cdk1 $[62,63]$. The switch from preIC to preIC ${ }^{*}$ depends on Cdc45 $[62,63]$. To simulate the switch from preRC to preIC, preRC was negatively regulated by preIC, and preIC was eliminated by selfdegradation. Finally, entry into $\mathrm{S}$-phase from preIC* depended on the function of Dbf4 [64]. Both preIC ${ }^{*}$ and $\mathrm{S}$-phase were terminated by a negative feedback loop from S-phase.

The $\mathrm{G} 2$ to anaphase transition (Figure $1 \mathrm{C}$ ): $\mathrm{Hcm} 1^{*}$ regulates the transcription of both NDD1 and FKH2 [13]. However, in cells deleted for HCM1 transcription remained periodic with a shift in peak time, indicating a combinatorial control by both $\mathrm{Hcm} 1$ and at least one other cell cycle-specific regulator that promotes transcription later in the cycle [13]. Because there is a nonperfect site for MBP in both NDD1 (at -556 ACGCGc instead of ACGCGT) and FKH2 (ACGCtT at -530), in the network regulations by both $\mathrm{Hcm}^{*}$ and $\mathrm{MBF}^{*}$ were added. We assume that the periodic expression of Ndd1, Fkh2 and Fkh2* are due to the intrinsic stability of the proteins. Fkh2 that functions as a negative regulator is converted into a positive one, designated Fkh2*, depending on phosphorylation by Clb5/Cdk [65].

The transcriptions of CLB2, SWI5 and CDC20 are negatively regulated by Fkh2, depending on the absence of $\mathrm{Cln} 1 / \mathrm{Cdk}$ activity [66]. Transcription is positively regulated by Ndd1 depending on Fkh2* (which recruits Ndd1 to the promoter). Transcription is also positively regulated by Fkh2* depending on $\operatorname{Ndd} 1[65,67,68]$. The transcription of CLB2 is initiated following entry into $\mathrm{S}$-phase, and is completed following the completion of $\mathrm{S}$-phase [19]. The use of a limited number of regulators in our network resulted in earlier expression of CLB2. In order to overcome this effect, we delayed the transcription of CLB2 by putting an upper threshold of 8 on its positive regulator $-\mathrm{Fkh} 2 \%$.

The periodic expression of $\mathrm{Clb} 2$ is regulated by Cdc20/APC [21,23]. The activity of Clb2/Cdk depends on the absence of Sic1 [21]. Swi5 level is periodic [69], but since its mode of regulation is not known, we assumed intrinsic stability. Activation of Cdc20, designated $\mathrm{Cdc} 20^{*}$ is via phosphorylation by $\mathrm{Clb} 2 / \mathrm{Cdk}$ $[22,70]$. We assume that $\mathrm{Cdc} 20$ and $\mathrm{Cdc} 20^{*}$ availability are regulated by a negative feedback from cPM (checkpoint M).

The transcription of SIC1 is positively regulated by Swi5 [71]. The stability of Sic1 is regulated following phosphorylation by $\mathrm{Cln} 1 / \mathrm{Cdk}$ [33]. In order to delay entry into S-phase until cells express $\mathrm{Cln} 1 / \mathrm{Cdk}$, in the simulation the initial state of SIC1 and Sic1 was 9. 
Entry into metaphase: (Figure 1C): Entry into metaphase depends on a checkpoint that monitors the completion of S-phase. This checkpoint was represented in the following simplified manner: We assume that $\mathrm{Clb} 2 /$ Cdk activates the $\mathrm{S}$ checkpoint (cPS) depending on S-phase. This checkpoint activates entry into metaphase depending on the completion (absence) of S phase [19]. We assigned the weight of that edge to 2, because in our simplified network many regulators required for entry into metaphase are missing, and thus the use of a single edge was unable to promote an increase of the metaphase node to 9 , whereas the use of level 2, sufficed. Down regulation of cPS is by metaphase, and metaphase is subject to negative auto-regulation.

The transcription factor that regulates the transcription of PDS1 is not known. Transcription profile resembles CLN1 transcription, however, neither SBF nor MBF bind to PDS1 promoter [53]. We assume that it is regulated by $\mathrm{Hcm}^{*}$ because it carries a consensus for its binding, atAAACAAa at -148 [consensus is AAAAACAAA [13]]. Protein availability is regulated by Cdc20*/APC [72]. The transcription of ESP1 is regulated by $\mathrm{Hcm} 1^{*}$ [13]. Esp1 is inactive in the presence of Pds1 [73]. We represent this regulation by the addition of an active Esp1 node whose presence depends on the absence of Pds1. We do not know how Esp1 and Esp1* availabilities are regulated; we assume negative feedback from cPM.

The activity of Cdh1 is positively regulated by $\mathrm{Cdc} 14$ and negatively regulated by both $\mathrm{Clb} 2 / \mathrm{Cdk}$ and $\mathrm{Clb} 5 /$ Cdk [74]. The activity of Cdc14 is positively regulated by Esp $^{*}$ and negatively by APC/Cdh1 [75].

Entry into anaphase also depends on a checkpoint. We assumed that this checkpoint (checkpoint $\mathrm{M}-\mathrm{cPM}$ ) is activated by Esp1* depending on entry into M-phase. Entry into anaphase is activated by this checkpoint depending on the completion of metaphase. In the network only limited number of regulators that activate anaphase were used, therefore, in order for anaphase to reach a maximal state of 9 , we used edge weight of 2 . Completion of both the checkpoint and anaphase is under negative feedback regulation from anaphase.

Regulation by pheromone: Under normal conditions the level of pheromone (excluded from Figure 1) was 0, while for the mating pheromone response its level was 9. Pheromone treatment results in inhibition of $\mathrm{Cln} 3 /$ $\mathrm{Cdk}$, and $\mathrm{Cln} 1 / \mathrm{Cdk}$ activity [26]. Our network does not include most of the details on how this signal is transmitted. Inhibition of Cln1/Cdk was mediated by Far1*. Pheromone regulates Far1* in two modes: Firstly, in response to pheromone treatment the transcription of FAR1 is induced [76], and the protein is activated following phosphorylation [24]. Finally, phosphorylation of Far1 and Far1* by Cln1/Cdk tags it for degradation [35].
The initial state of Nitrogen depletion signal was 9 , and it was represented as N. This node repressed Cln3 along with $\mathrm{Cln} 3 / \mathrm{Cdk}$, and either $\mathrm{Cln} 1$ along with $\mathrm{Cln} 1 /$ Cdk, or SIC1, according to the hypotheses examined (see Table 1 and text).

\section{Additional file}

Additional file 1: Tool manual.

\section{Competing interests}

The authors declare that they have no competing interests.

\section{Authors' contribution}

$\mathrm{AR}$ and $\mathrm{OH}$ implemented the computational model. YK constructed the network and conducted simulations. AR and $Y K$ analyzed simulations results. $A R, Y K, R P$ and $B C$ designed research methodology. AR and YK wrote the manuscript. All authors gave intellectual input and comments on the manuscript. All authors read and approved the final manuscript.

\section{Acknowledgments}

This work was supported by grant from the Israel Science Foundation to Y.K. and R.Y.P., and a fellowship from the Edmond J. Safra Center for Bioinformatics at Tel-Aviv University to A.R. We thank Curt Wittenberg, Itay Yanai and Ester Lubzens for critical reading of the manuscript.

\section{Author details}

${ }^{1}$ School of Computer Science, Tel Aviv University, Tel Aviv 69978, Israel. ${ }^{2}$ Department of Mathematics, Ort Braude College, Karmiel 21982, Israel. ${ }^{3}$ Department of Computer Science, Technion - Israel Institute of Technology, Haifa 3200003, Israel. ${ }^{4}$ Department of Biology, Technion - Israel Institute of Technology, Haifa 3200003, Israel.

Received: 21 July 2013 Accepted: 31 July 2013

Published: 6 August 2013

\section{References}

1. Freeman M: Feedback control of intercellular signalling in development. Nat Geosci 2000, 408(6810):313-319.

2. Smolen $\mathrm{P}$, Baxter DA, Byrne $\mathrm{JH}$ : Mathematical modeling of gene networks. Neuron 2000, 26(3):567-580.

3. Karlebach G, Shamir R: Modelling and analysis of gene regulatory networks. Nat Rev Mol Cell Biol 2008, 9(10):770-780.

4. Mogilner A, Allard J, Wollman R: Cell polarity: quantitative modeling as a tool in cell biology. Science 2012, 336(6078):175-179.

5. Morelli LG, Uriu K, Ares S, Oates AC: Computational approaches to developmental patterning. Science 2012, 336(6078):187-191.

6. Munsky B, Neuert $G$, van Oudenaarden A: Using gene expression noise to understand gene regulation. Science 2012, 336(6078):183-187.

7. Rubinstein A, Gurevich V, Kasulin-Boneh Z, Pnueli L, Kassir Y, Pinter RY: Faithful modeling of transient expression and its application to elucidating negative feedback regulation. Proc Natl Acad Sci U S A 2007, 104(15):6241-6246.

8. Schaub MA, Henzinger TA, Fisher J: Qualitative networks: a symbolic approach to analyze biological signaling networks. BMC Syst Bio/ 2007, 1:4.

9. Hartwell LH, Culotti J, Pringle JR, Reid BJ: Genetic control of the cell division cycle in yeast. Science 1974, 183(4120):46-51.

10. Zhou BB, Elledge SJ: The DNA damage response: putting checkpoints in perspective. Nat Geosci 2000, 408(6811):433-439.

11. Nasmyth K: At the heart of the budding yeast cell cycle. Trends Genet 1996, 12(10):405-412.

12. Morgan DO: Cyclin-dependent kinases: engines, clocks, and microprocessors. Annu Rev Cell Dev Biol 1997, 13:261-291.

13. Pramila T, Wu W, Miles S, Noble WS, Breeden LL: The Forkhead transcription factor $\mathrm{Hcm} 1$ regulates chromosome segregation genes and fills the S-phase gap in the transcriptional circuitry of the cell cycle. Genes Dev 2006, 20(16):2266-2278. 
14. Weinreich M, Liang C, Stillman B: The Cdc6p nucleotide-binding motif is required for loading $\mathrm{mcm}$ proteins onto chromatin. Proc Natl Acad Sci USA 1999, 96(2):441-446.

15. Piatti S, Lengauer $C$, Nasmyth $\mathrm{K}$ : Cdc6 is an unstable protein whose de novo synthesis in $\mathrm{G} 1$ is important for the onset of $S$ phase and for preventing a 'reductional' anaphase in the budding yeast Saccharomyces cerevisiae. Embo J 1995, 14(15):3788-3799.

16. Cocker JH, Piatti S, Santocanale C, Nasmyth K, Diffley JF: An essential role for the Cdc6 protein in forming the pre-replicative complexes of budding yeast. Nat Geosci 1996, 379(6561):180-182.

17. Tanaka T, Knapp D, Nasmyth K: Loading of an Mcm protein onto DNA replication origins is regulated by Cdc6p and CDKs. Cell 1997, 90(4):649-660.

18. Hartwell L: Sequential function of gene products relative to DNA synthesis in the yeast cell cycle. J Mol Biol 1976, 104(4):803-817.

19. Richardson H, Lew DJ, Henze M, Sugimoto K, Reed SI: Cyclin-B homologs in Saccharomyces cerevisiae function in S phase and in G2. Genes Dev 1992, 6(11):2021-2034.

20. Visintin R, Prinz S, Amon A: CDC20 and CDH1: a family of substratespecific activators of APC-dependent proteolysis. Science 1997, 278(5337):460-463.

21. Wasch R, Cross FR: APC-dependent proteolysis of the mitotic cyclin Clb2 is essential for mitotic exit. Nat Geosci 2002, 418(6897):556-562.

22. Rudner AD, Murray AW: Phosphorylation by Cdc28 activates the Cdc20dependent activity of the anaphase-promoting complex. J Cell Biol 2000, 149(7):1377-1390.

23. Irniger $\mathrm{S}$, Nasmyth $\mathrm{K}$ : The anaphase-promoting complex is required in $\mathrm{G}$ arrested yeast cells to inhibit B-type cyclin accumulation and to prevent uncontrolled entry into S-phase. J Cell Sci 1997, 110(13):1523-1531.

24. Peter M, Herskowitz I: Direct inhibition of the yeast cyclin-dependent kinase Cdc28-Cln by Far1. Science 1994, 265(5176):1228-1231.

25. Jeoung DI, Oehlen LJ, Cross FR: Cln3-associated kinase activity in Saccharomyces cerevisiae is regulated by the mating factor pathway. Mol Cell Biol 1998, 18(1):433-441.

26. Tyers $M$, Futcher B: Far1 and Fus3 link the mating pheromone signal transduction pathway to three G1-phase Cdc28 kinase complexes. Mol Cell Biol 1993, 13(9):5659-5669.

27. Dirick L, Nasmyth K: Positive feedback in the activation of $\mathrm{G} 1$ cyclins in yeast. Nat Geosci 1991, 351(6329):754-757.

28. Stuart D, Wittenberg C: CLN3, not positive feedback, determines the timing of CLN2 transcription in cycling cells. Genes Dev 1995, 9(22):2780-2794.

29. Skotheim JM, Di Talia S, Siggia ED, Cross FR: Positive feedback of G1 cyclins ensures coherent cell cycle entry. Nat Geosci 2008, 454(7202):291-296.

30. Schwob E, Bohm T, Mendenhall MD, Nasmyth K: The B-type cyclin kinase inhibitor p40SIC1 controls the G1 to S transition in S. cerevisiae. Cell 1994, 79(2):233-244.

31. Pathak R, Blank HM, Guo J, Ellis S, Polymenis M: The Dcr2p phosphatase destabilizes Sic1p in Saccharomyces cerevisiae. Biochem Biophys Res Commun 2007, 361(3):700-704

32. Tyers M: The cyclin-dependent kinase inhibitor p40SIC1 imposes the requirement for Cln G1 cyclin function at Start. Proc Natl Acad Sci USA 1996, 93(15):7772-7776.

33. Nishizawa M, Kawasumi M, Fujino M, Toh-e A: Phosphorylation of sic1, a cyclin-dependent kinase (Cdk) inhibitor, by Cdk including Pho85 kinase is required for its prompt degradation. Mol Biol Cell 1998, 9 (9):2393-2405

34. Doncic A, Falleur-Fettig M, Skotheim JM: Distinct interactions select and maintain a specific cell fate. Mol Cell 2011, 43(4):528-539.

35. Henchoz S, Chi Y, Catarin B, Herskowitz I, Deshaies RJ, Peter M: Phosphorylationand ubiquitin-dependent degradation of the cyclin- dependent kinase inhibitor Far1p in budding yeast. Genes Dev 1997, 11(22):3046-3060.

36. Pringle JR, Hartwell LH: The Saccharomyces cerevisiae cell cycle. In The Molecular Biology of the Yeast Saccharomyces cerevisiae. Edited by Strathern JN, Jones EW, Broach JR. Cold Spring Harbor: Life Cycle and Inheritance Cold Spring Harbor Laboratory Press; 1981:97-142. ISBN I.

37. Gallego C, Gari E, Colomina N, Herrero E, Aldea M: The Cln3 cyclin is downregulated by translational repression and degradation during the $\mathrm{G} 1$ arrest caused by nitrogen deprivation in budding yeast. EMBO J 1997, 16(23):7196-7206

38. Wang H, Gari E, Verges E, Gallego C, Aldea M: Recruitment of Cdc28 by Whi3 restricts nuclear accumulation of the $\mathrm{G} 1$ cyclin-Cdk complex to late G1. EMBO J 2004, 23(1):180-190.
39. Hadwiger JA, Wittenberg C, Richardson HE, de Barros LM, Reed SI: A family of cyclin homologs that control the G1 phase in yeast. Proc Natl Acad Sci U S A 1989, 86(16):6255-6259.

40. Ubersax JA, Woodbury EL, Quang PN, Paraz M, Blethrow JD, Shah K, Shokat KM, Morgan DO: Targets of the cyclin-dependent kinase Cdk1. Nat Geosci 2003, 425(6960):859-864.

41. Fawcett TW, Higginson AD: Heavy use of equations impedes communication among biologists. Proc Natl Acad Sci USA 2012, 109(29):11735-11739.

42. May RM: Uses and abuses of mathematics in biology. Science 2004, 303(5659):790-793

43. Pramila T, Miles S, GuhaThakurta D, Jemiolo D, Breeden LL: Conserved homeodomain proteins interact with MADS box protein $\mathrm{Mcm} 1$ to restrict $E C B$-dependent transcription to the $M / G 1$ phase of the cell cycle. Genes Dev 2002, 16(23):3034-3045.

44. Polymenis M, Schmidt EV: Coupling of cell division to cell growth by translational control of the G1 cyclin CLN3 in yeast. Genes Dev 1997 , 11(19):2522-2531.

45. Barbet NC, Schneider U, Helliwell SB, Stansfield I, Tuite MF, Hall MN: TOR controls translation initiation and early $\mathrm{G} 1$ progression in yeast. Mol Biol Cell 1996, 7(1):25-42

46. Yaglom J, Linskens MH, Sadis S, Rubin DM, Futcher B, Finley D: p34Cdc28mediated control of Cln3 cyclin degradation. Mol Cell Biol 1995, 15(2):731-741.

47. de Bruin RA, McDonald WH, Kalashnikova TI, Yates J 3rd, Wittenberg C: CIn3 activates G1-specific transcription via phosphorylation of the SBF bound repressor Whi5. Cell 2004, 117(7):887-898.

48. Andrews BJ, Herskowitz I: Identification of a DNA binding factor involved in cell-cycle control of the yeast HO gene. Cell 1989, 57(1):21-29.

49. Nasmyth K, Dirick L: The role of SW14 and SW16 in the activity of G1 cyclins in yeast. Cell 1991, 66(5):995-1013.

50. Eser U, Falleur-Fettig M, Johnson A, Skotheim JM: Commitment to a cellular transition precedes genome-wide transcriptional change. Mol Cell 2011, 43(4):515-527.

51. Koch C, Schleiffer A, Ammerer G, Nasmyth K: Switching transcription on and off during the yeast cell cycle: $\mathrm{Cln} / \mathrm{Cdc} 28$ kinases activate bound transcription factor SBF (Swi4/Swi6) at start, whereas Clb/Cdc28 kinases displace it from the promoter in G2. Genes Dev 1996, 10(2):129-141.

52. Geymonat M, Spanos A, Wells GP, Smerdon SJ, Sedgwick SG: Clb6/Cdc28 and $\mathrm{Cdc} 14$ regulate phosphorylation status and cellular localization of Swi6. Mol Cell Biol 2004, 24(6):2277-2285.

53. Iyer VR, Horak CE, Scafe CS, Botstein D, Snyder M, Brown PO: Genomic binding sites of the yeast cell-cycle transcription factors SBF and MBF. Nat Geosci 2001, 409(6819):533-538.

54. Bean JM, Siggia ED, Cross FR: High functional overlap between Mlul cellcycle box binding factor and Swi4/6 cell-cycle box binding factor in the $\mathrm{G} 1 / \mathrm{S}$ transcriptional program in Saccharomyces cerevisiae. Genetics 2005, 171(1):49-61.

55. Ogas J, Andrews BJ, Herskowitz I: Transcriptional activation of CLN1, CLN2, and a putative new G1 cyclin (HCS26) by SWI4, a positive regulator of G1-specific transcription. Cell 1991, 66(5):1015-1026.

56. de Bruin RA, Kalashnikova TI, Chahwan C, McDonald WH, Wohlschlegel J, Yates J 3rd, Russell P, Wittenberg C: Constraining G1-specific transcription to late $\mathrm{G} 1$ phase: the MBF-associated corepressor Nrm1 acts via negative feedback. Mol Cell 2006, 23(4):483-496.

57. Ostapenko D, Solomon MJ: Anaphase promoting complex-dependent degradation of transcriptional repressors Nrm1 and Yhp1 in Saccharomyces cerevisiae. Mol Biol Cell 2011, 22(13):2175-2184.

58. Sari F, Braus GH, Irniger S: A process independent of the anaphasepromoting complex contributes to instability of the yeast $\mathrm{S}$ phase cyclin Clb5. J Biol Chem 2007, 282(36):26614-26622.

59. Piatti S, Bohm T, Cocker JH, Diffley JF, Nasmyth K: Activation of S-phasepromoting CDKs in late G1 defines a "point of no return" after which Cdc6 synthesis cannot promote DNA replication in yeast. Genes Dev 1996, 10(12):1516-1531.

60. Drury LS, Perkins G, Diffley JF: The cyclin-dependent kinase Cdc28p regulates distinct modes of $C d c 6 p$ proteolysis during the budding yeast cell cycle. Curr Biol 2000, 10(5):231-240.

61. Spellman PT, Sherlock $G$, Zhang MQ, Iyer VR, Anders $K$, Eisen MB, Brown PO, Botstein D, Futcher B: Comprehensive identification of cell cycleregulated genes of the yeast Saccharomyces cerevisiae by microarray hybridization. Mol Biol Cell 1998, 9(12):3273-3297. 
62. Nougarede R, Della Seta F, Zarzov P, Schwob E: Hierarchy of S-phase-promoting factors: yeast $\mathrm{Dbf} 4-\mathrm{Cdc} 7$ kinase requires prior S-phase cyclin-dependent kinase activation. Mol Cell Biol 2000, 20(11):3795-3806.

63. Bell SP, Dutta A: DNA replication in eukaryotic cells. Annu Rev Biochem 2002, 71:333-374.

64. Owens JC, Detweiler CS, Li JJ: CDC45 is required in conjunction with CDC7/DBF4 to trigger the initiation of DNA replication. Proc Natl Acad Sci USA 1997, 94(23):12521-12526.

65. Pic-Taylor A, Darieva Z, Morgan BA, Sharrocks AD: Regulation of cell cyclespecific gene expression through cyclin-dependent kinase-mediated phosphorylation of the forkhead transcription factor Fkh2p. Mol Cell Biol 2004, 24(22):10036-10046.

66. Veis J, Klug H, Koranda M, Ammerer G: Activation of the G2/M-specific gene CLB2 requires multiple cell cycle signals. Mol Cell Biol 2007, 27(23):8364-8373.

67. Kumar R, Reynolds DM, Shevchenko A, Goldstone SD, Dalton S: Forkhead transcription factors, Fkh1p and Fkh2p, collaborate with Mcm1p to control transcription required for M-phase. Curr Biol 2000, 10(15):896-906.

68. Koranda M, Schleiffer A, Endler L, Ammerer G: Forkhead-like transcription factors recruit Ndd1 to the chromatin of G2/M-specific promoters. Nat Geosci 2000, 406(6791):94-98.

69. Kishi T, Ikeda A, Koyama N, Fukada J, Nagao R: A refined two-hybrid system reveals that $\mathrm{SCF}(\mathrm{Cdc} 4)$-dependent degradation of Swi5 contributes to the regulatory mechanism of S-phase entry. Proc Natl Acad Sci U S A 2008, 105(38):14497-14502.

70. Cross FR: Two redundant oscillatory mechanisms in the yeast cell cycle. Dev Cell 2003, 4(5):741-752.

71. Knapp D, Bhoite L, Stillman DJ, Nasmyth K: The transcription factor Swi5 regulates expression of the cyclin kinase inhibitor p40SIC1. Mol Cell Biol 1996, 16(10):5701-5707.

72. Cohen-Fix O, Peters JM, Kirschner MW, Koshland D: Anaphase initiation in Saccharomyces cerevisiae is controlled by the APC-dependent degradation of the anaphase inhibitor Pds1p. Genes Dev 1996, 10(24):3081-3093.

73. Ciosk R, Zachariae W, Michaelis C, Shevchenko A, Mann M, Nasmyth K: An ESP1/PDS1 complex regulates loss of sister chromatid cohesion at the metaphase to anaphase transition in yeast. Cell 1998, 93(6):1067-1076.

74. Jaspersen S, Charles JF, Morgan DO: Inhibitory phosphorylation of the APC regulator $\mathrm{Hct} 1$ is controlled by the kinase $\mathrm{Cdc} 28$ and the phosphatase Cdc14. Curr Biol 1999, 9(5):227-236.

75. Visintin C, Tomson BN, Rahal R, Paulson J, Cohen M, Taunton J, Amon A, Visintin R: APC/C-Cdh1-mediated degradation of the Polo kinase Cdc5 promotes the return of Cdc14 into the nucleolus. Genes Dev 2008, 22(1):79-90

76. Chang F, Herskowitz I: Identification of a gene necessary for cell cycle arrest by a negative growth factor of yeast: FAR1 is an inhibitor of a G1 cyclin, CLN2. Cell 1990, 63(5):999-1011.

doi:10.1186/1756-0500-6-311

Cite this article as: Rubinstein et al:: The effective application of a discrete transition model to explore cell-cycle regulation in yeast. BMC Research Notes 2013 6:311.

\section{Submit your next manuscript to BioMed Central and take full advantage of:}

- Convenient online submission

- Thorough peer review

- No space constraints or color figure charges

- Immediate publication on acceptance

- Inclusion in PubMed, CAS, Scopus and Google Scholar

- Research which is freely available for redistribution 